Research, part of a Special Feature on Effects of Roads and Traffic on Wildlife Populations and Landscape Function

\title{
Evidence that a Highway Reduces Apparent Survival Rates of Squirrel Gliders
}

\author{
Sarah C. McCall ${ }^{1,2}$, Michael A. McCarthy ${ }^{2}, \underline{\text { Rodney van der Ree }}^{1,2}$, Michael J. Harper ${ }^{1,3}$, \\ Silvana Cesarini ${ }^{4}$, and Kylie Soanes ${ }^{1}$
}

\begin{abstract}
Roads and traffic are prominent components of most landscapes throughout the world, and their negative effects on the natural environment can extend for hundreds or thousands of meters beyond the road. These effects include mortality of wildlife due to collisions with vehicles, pollution of soil and air, modification of wildlife behavior in response to noise, creation of barriers to wildlife movement, and establishment of dispersal conduits for some plant and animal species. In southeast Australia, much of the remaining habitat for the squirrel glider, Petaurus norfolcensis, is located in narrow strips of Eucalyptus woodland that is adjacent to roads and streams, as well as in small patches of woodland vegetation that is farther from roads. We evaluated the effect of traffic volume on squirrel gliders by estimating apparent annual survival rates of adults along the Hume Freeway and nearby low-traffic-volume roads. We surveyed populations of squirrel gliders by trapping them over 2.5 years, and combined these data with prior information on apparent survival rates in populations located away from freeways to model the ratio of apparent annual survival rates in both site types. The apparent annual survival rate of adult squirrel gliders living along the Hume Freeway was estimated to be approximately $60 \%$ lower than for squirrel gliders living near local roads. The cause of the reduced apparent survival rate may be due to higher rates of mortality and/or higher emigration rates adjacent to the Hume Freeway compared with populations near smaller country roads. Management options for population persistence will be influenced by which of these factors is the primary cause of a reduced apparent survival rate.
\end{abstract}

Key Words: Australia; emigration; mortality; population persistence; road ecology; squirrel glider; survival

\section{INTRODUCTION}

The global decline in biodiversity is directly linked to anthropogenic activities such as the modification of landscapes and environmental systems (Kerr and Currie 1995, Lande 1998). Increasing human population size and technological advancement fuels the development of agriculture, housing, industries, forestry, mining, and transportation infrastructure like roads (Turner II et al. 1990). The impacts of roads and traffic on the natural environment are numerous and may extend for many hundreds or even thousands of meters beyond the road (Forman and Deblinger 2000). These impacts include mortality of wildlife due to collisions with vehicles (Groot Bruinderink and
Hazebroek 1996, Huijser et al. 2009), pollution of soil and air (Bernhardt-Römermann et al. 2006, Bignal et al. 2007), modification of wildlife behavior in response to noise (Parris et al. 2009, Parris and Schneider 2009), creation of barriers to wildlife movement (Merriam et al. 1989, Kerth and Melber 2009), and establishment of dispersal conduits for some plant and animal species (Parendes and Jones 2000, Brown et al. 2006). Much attention has focused on the rate, magnitude, and financial cost of mortality of wildlife due to collisions with vehicles, particularly in Europe and North America where a collision with a large animal impacts human welfare (e.g., Groot Bruinderink and Hazebroek 1996, Huijser et al. 2009). However, factors such as the removal of roadkill by scavengers

\footnotetext{
${ }^{1}$ Australian Research Centre for Urban Ecology, ${ }^{2}$ School of Botany, University of Melbourne, ${ }^{3}$ Department of Sustainability and Environment, Victoria, ${ }^{4}$ School of Biological Scienes, Monash University
} 
(Row et al. 2007), movement of animals away from roads after collision, and inconspicuousness of the affected species reduces the detectability of roadkill, making it difficult to estimate the full magnitude of its effect on mortality rates (but see Row et al. [2007] who used radio-tracking to determine crossing rates and roadkill events as a means of calculating the rate of road-related mortality).

Population studies are an alternative method of quantifying impacts such as road mortality on small species, with differences in demographic rates across space and through time indicating ecological effects (Ruggiero et al. 1994, Marschall and Crowder 1996, Gill et al. 2001, Converse et al. 2005, Yasué and Dearden 2006). These demographic rates may also inform research on the dynamics of population size (McCallum 2000), and assessments of population viability (Akçakaya and SjögrenGulve 2000), in turn providing information to assist management decisions (Drechsler and Burgman 2004, van der Grift and Pouwels 2006).

The squirrel glider (Petaurus norfolcensis) is a small (190-300 g) arboreal marsupial found in open forest and woodland in eastern Australia (Claridge and van der Ree 2004, van der Ree and Suckling 2008). Extensive clearing of habitat for agriculture has reduced the continuity of squirrel glider habitat, and in many regions this species is now limited to a network of small and often isolated woodland remnants. In some locations, particularly in southeast Australia, much of this remnant habitat occurs as linear strips next to roads and watercourses (van der Ree et al. 2003). The long-term demographic impact that roads of varying width and traffic volume have on squirrel gliders is unknown. Observations (albeit infrequently) of dead squirrel gliders (presumably hit by a vehicle) on a large freeway suggests that these factors could influence the species' mortality rate (van der Ree 2006). Squirrel gliders travel primarily by gliding from tree to tree. Depending on the launch height and required distance to traverse the road, an animal's landing height may mean it is directly in front of vehicles at some point in the glide. Squirrel gliders that are hit by vehicles are difficult to detect because their small body size makes them likely to be thrown from the road, rendered unidentifiable if they remain on the road, or in some cases, remain attached to vehicles after collision. Rather than rely on assessing rates of mortality directly, we evaluated the impact of the Hume Freeway on the apparent survival rate of adult squirrel gliders by conducting a mark-recapture study over 2.5 years. This impact was evaluated by comparing the apparent survival rate of populations near and far from the freeway. Within a Bayesian analytical framework we also examined whether incorporating prior information on survival rates in the absence of a freeway reduces uncertainty about the impact of this road.

\section{METHODS}

\section{Study area}

Populations of squirrel gliders were surveyed along the Hume Freeway between the towns of Avenel $\left(33^{\circ} 42^{\prime} \mathrm{S}, 148^{\circ} 76^{\prime} \mathrm{E}\right)$ and Benalla $\left(36^{\circ} 55^{\prime} \mathrm{S}, 145^{\circ}\right.$ $98^{\prime}$ E) in southeast Australia. Seven sites were surveyed: three sites at the Hume Freeway (freeway sites: F1, F2, F3), and four sites at least five kilometers from the freeway (control sites: C1, C2, C3, C4) (Fig. 1). The number of sites was limited by availability of suitable areas and logistic constraints. At both site types, squirrel gliders were surveyed by trapping within strips of Eucalyptus woodland located along local roads with traffic volumes of less than 100 cars per day. At freeway sites, these local roads were intersected by the Hume Freeway; control sites were intersected by another local road or unused road reserve. Unused road reserves are areas that were set aside with the intent of future road construction; however, that intent has not yet been carried forth.

Major differences between the freeway and control sites were traffic volume and width of the intersecting road. Average traffic volume along the Hume Freeway was 10,000 vehicles per day, and at control sites was less than 100 vehicles per day (zero vehicles along unused road reserves). The Hume Freeway was dual carriageway, with each carriageway $12-14 \mathrm{~m}$ wide and separated by a center median approximately $30-50 \mathrm{~m}$ wide. The vegetation of this center median varied, and included mown grasses, both remnant and regrowth Eucalyptus woodland, and planted trees and shrubs (both indigenous and exotic species). The median at our freeway sites supported mature remnant woodland at site F1, and shrubs and young regrowth at F2 and F3. The intersecting local roads were single lane, approximately $4 \mathrm{~m}$ wide, and lined on either side with a strip of remnant vegetation. Unused road reserves had no road; those used in this 
Fig. 1. Location of sample populations of squirrel gliders (Petaurus norfolcensis) in southeast Australia: $\mathrm{C} 1 \mathrm{C} 2, \mathrm{C} 3$, and $\mathrm{C} 4$ refer to control populations; F1, F2, and F3 refer to freeway populations.

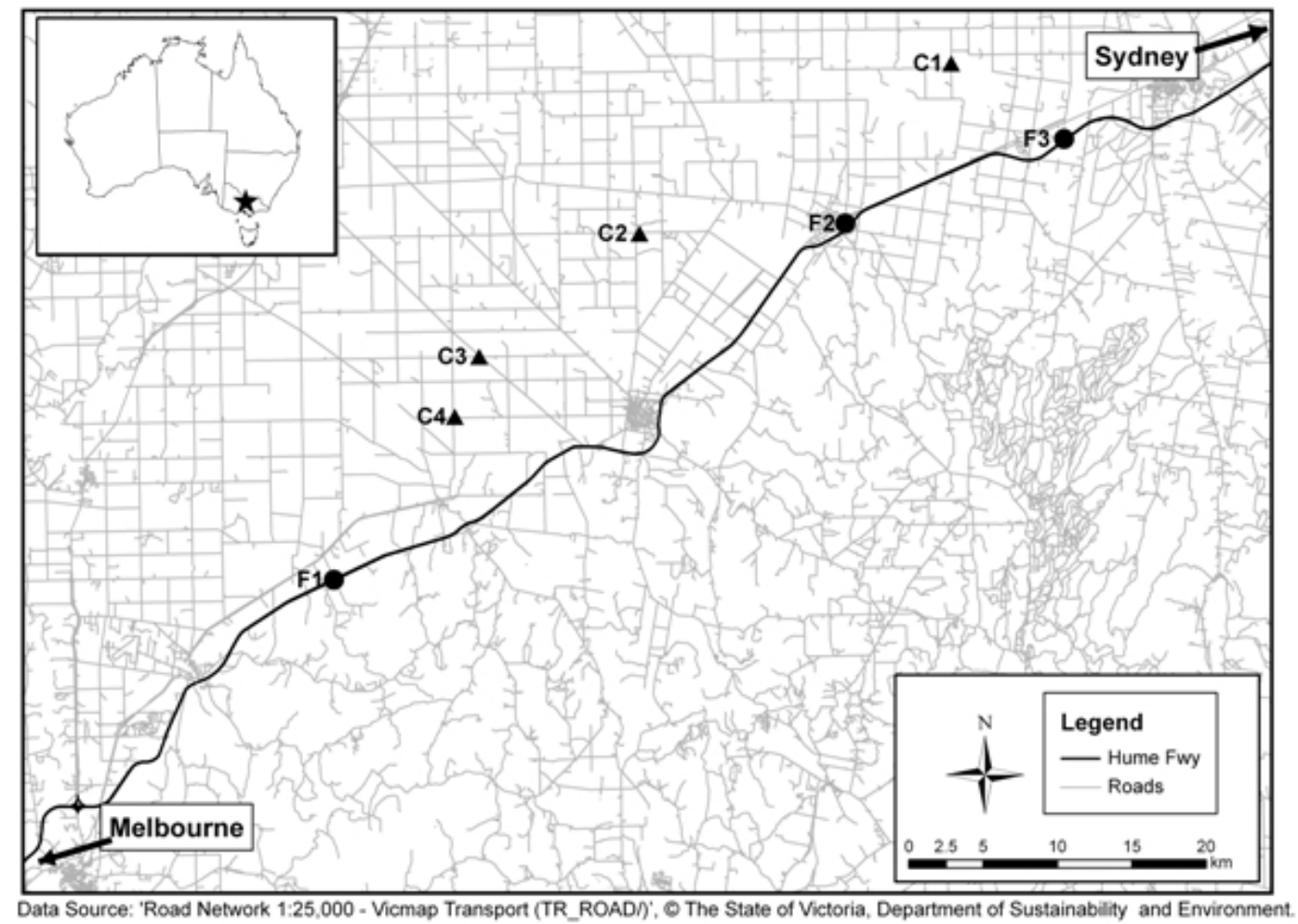

study were characterized as a strip of remnant vegetation. The legal speed limit was $110 \mathrm{~km} / \mathrm{h}$ along the freeway, and between $60 \mathrm{~km} / \mathrm{h}$ and 100 $\mathrm{km} / \mathrm{h}$ at control sites.

\section{Trapping}

Wire cage traps $(20 \times 20 \times 50 \mathrm{~cm})$ were nailed to tree trunks at a height of 2-5 $\mathrm{m}$ and were baited with a mix of rolled oats, honey, and peanut butter. A mixture of one part honey to three parts water was sprayed on the tree trunk to attract animals to the trap. Traps were covered with plastic to protect captured animals from wind and rain. The number of traps and the duration of trapping at each site varied slightly because some earlier surveys were conducted primarily for other reasons. Traps were set $50 \mathrm{~m}$ apart in all sites except control site C4, where traps were spaced at $25 \mathrm{~m}$ intervals. Twenty to 24 traps were set at all freeway sites and at control site C4. Ten to 14 traps were typically set at the remaining control sites (Table 1). The line of traps along the intersecting roads began within $50 \mathrm{~m}$ of the Hume Freeway (freeway sites) or local road/ road reserve (control sites).

Trapping effort also varied over time, with initial trapping sessions typically shorter than subsequent trapping. Trapping sessions ranged from 2 to 11 consecutive nights (Table 1). To account for this variation in trapping effort when estimating parameters, each night of trapping was treated as 
Table 1. Trapping effort during census of squirrel glider (Petaurus norfolcensis) populations in southeast Australia. Trapping effort is the number of nights of trapping multiplied by the number of traps open, accounting for instances when a proportion of traps (in some cases, all traps) were closed on a given night. The first survival period includes trapping sessions between August 2005 and December 2006; the second includes trapping sessions between January 2007 and February 2008.

\begin{tabular}{|c|c|c|c|c|c|}
\hline Site type & Site & Time period of trapping session & $\begin{array}{l}\text { Survival } \\
\text { period }\end{array}$ & $\begin{array}{l}\text { Number of } \\
\text { nights }\end{array}$ & $\begin{array}{c}\text { Trapping } \\
\text { effort }\end{array}$ \\
\hline \multirow[t]{17}{*}{ Control sites } & \multirow[t]{3}{*}{$\mathrm{C} 1$} & $12 / 12 / 2005-15 / 12 / 2005$ & 1 & 4 & 40 \\
\hline & & $16 / 11 / 2006-22 / 11 / 2006$ & 1 & 7 & 98 \\
\hline & & $8 / 01 / 2008-16 / 01 / 2008$ & 2 & 9 & 126 \\
\hline & \multirow[t]{6}{*}{$\mathrm{C} 2$} & $6 / 12 / 2005-9 / 12 / 2005$ & 1 & 4 & 40 \\
\hline & & $13 / 12 / 2005-14 / 12 / 2005$ & 1 & 2 & 16 \\
\hline & & $27 / 01 / 2006-14 / 02 / 2006$ & 1 & 9 & 104 \\
\hline & & $28 / 04 / 2006-2 / 05 / 2006$ & 1 & 5 & 48 \\
\hline & & $4 / 12 / 2006-10 / 12 / 2006$ & 1 & 7 & 98 \\
\hline & & $11 / 01 / 2008-19 / 01 / 2008$ & 2 & 9 & 126 \\
\hline & \multirow[t]{3}{*}{$\mathrm{C} 3$} & $6 / 12 / 2005-9 / 12 / 2005$ & 1 & 4 & 40 \\
\hline & & $29 / 11 / 2006-4 / 12 / 2006$ & 1 & 6 & 84 \\
\hline & & $3 / 02 / 2008-10 / 02 / 2008$ & 2 & 8 & 112 \\
\hline & \multirow[t]{4}{*}{$\mathrm{C} 4$} & $9 / 02 / 2006-13 / 02 / 2006$ & 1 & 5 & 100 \\
\hline & & $1 / 08 / 2006-5 / 08 / 2006$ & 1 & 10 & 142 \\
\hline & & $5 / 12 / 2006-9 / 12 / 2006$ & 1 & 5 & 120 \\
\hline & & $19 / 01 / 2008-31 / 01 / 2008$ & 2 & 11 & 1294 \\
\hline & \multicolumn{2}{|c|}{ Total for control sites: } & - & 105 & 2588 \\
\hline \multirow[t]{5}{*}{ Freeway sites } & \multirow[t]{5}{*}{$\mathrm{F} 1$} & $3 / 08 / 2005-9 / 08 / 2005$ & 1 & 7 & 168 \\
\hline & & $25 / 10 / 2005-28 / 10 / 2005$ & 1 & 4 & 80 \\
\hline & & $19 / 12 / 2005-23 / 12 / 2005$ & 1 & 5 & 77 \\
\hline & & $16 / 01 / 2006-19 / 01 / 2006$ & 1 & 4 & 64 \\
\hline & & $17 / 05 / 2006-20 / 05 / 2006$ & 1 & 4 & 45 \\
\hline
\end{tabular}




\begin{tabular}{|c|c|c|c|c|}
\hline & $9 / 08 / 2006-10 / 08 / 2006$ & 1 & 2 & 12 \\
\hline & $25 / 11 / 2006-1 / 12 / 2006$ & 1 & 7 & 168 \\
\hline & $4 / 02 / 2008-12 / 02 / 2008$ & 2 & 9 & 216 \\
\hline $\mathrm{F} 2$ & $10 / 01 / 2006-13 / 01 / 2006$ & 1 & 4 & 80 \\
\hline & $15 / 11 / 2006-22 / 11 / 2006$ & 1 & 8 & 192 \\
\hline & $22 / 01 / 2008-1 / 02 / 2008$ & 2 & 8 & 192 \\
\hline F3 & 19/01/2006 - 24/01/2006 & 1 & 4 & 80 \\
\hline & 9/12/2006 - 13/12/2006 & 1 & 5 & 120 \\
\hline & $9 / 01 / 2008-17 / 01 / 2008$ & 2 & 9 & 216 \\
\hline for & & - & 80 & 1710 \\
\hline
\end{tabular}

one sample unit. The first trapping sessions occurred in August 2005. By December 2006, all sample sites had a minimum of two trapping sessions, and by February 2008, all had been sampled at least three times. Parameter estimates from a mark-recapture model were compared between these two time periods - August 2005 to December 2006 and January 2007 to February 2008 - to determine if there was any pattern in estimates of apparent survival rates.

Traps were set before dusk and checked at dawn each day, with all captured animals processed and released where each was trapped. For each animal, a unique combination of numbers and letters was tattooed in the ear flap, two 2-mm notches were removed from the margin of the ear flap (collected for a genetics study), and a microchip was inserted below the skin (OTrovan ID100). Each animal was measured, weighed, and assigned to an age class $(<1$ year, 1-2 years, 2-3 years, or $>3$ years) based on the criteria of tooth wear, body mass, and reproductive condition as described by van der Ree (2002). An animal was considered to be a juvenile if it was assigned to the $<1$ year age class.

\section{Statistical analyses}

\section{Mark-recapture model}

A mark-recapture model was used to estimate the apparent annual survival rate and the relative apparent survival rate of male and female squirrel gliders that were in the adult age class. The apparent annual survival rate (hereafter referred to as the annual survival rate) is the proportion of individuals that survive for a year and do not leave the study area. The relative apparent survival rate is the ratio of apparent annual survival rates in freeway populations versus control populations. The data used were the individual capture histories of each adult squirrel glider. The capture history recorded the capture status (trapped or not) of each squirrel glider on nights when trapping occurred at any of the seven sites.

The mark-recapture models included two components: the probability of survival of individuals from one trap night to the next, and the probability of recapture of each individual on each trap night conditional on it being alive on the night of trapping (the probability of recapture). We effectively treated permanent migration from the site as death because we were modeling the apparent survival rate. The probability of capturing an individual on a particular night (conditional on it being alive the previous time the site was trapped) 
equals the probability that it survived the period from the last trapping session (a function of the annual survival rate) multiplied by the probability that it would be captured given it was alive (the probability of recapture). We considered models in which the probability of recapture and the probability of survival varied among trapping nights, individuals, and sites by including these influences as random effects. Random effects were assumed to be normally distributed (on the logit scale) with a mean of zero and a standard deviation that was estimated. We also included a fixed effect for sites at the Hume Freeway and control sites, and a fixed effect for sex to account for possible differences in the probabilities of survival and capture between males and females. Different combinations of models with and without the various random effects were considered, although not all of the random effects could be estimated reliably, so we confined our analysis to a reduced model. This model included random effects of site, individual, and night for recapture probability, so it helped accommodate possible differences in trappability among different individuals. The models did not include random effects for survival. Different survival rates for the two different periods were included, which would account for changes in dispersal and mortality over time. Thus, the annual probability of survival of individual $i\left(s_{i}\right)$ depended on its sex $\left(\operatorname{sex}_{i}\right)$ and whether or not it occurred at a freeway $\left(\right.$ freeway $\left._{i}\right)$, "Eq. 1":

$$
\operatorname{logit}\left(s_{i}\right)=\operatorname{logit}\left(S_{\text {sex }_{i}, \text { freeway }}\right)
$$

where $S_{j, k}$ is the annual probability of survival of individuals of $\operatorname{sex} j$ at site type $k$.

The probability of an individual $i\left(d_{i, j, k}\right)$ being recaptured (conditional on it being alive) was a function of its sex $\left(\operatorname{sex}_{i}\right)$ and whether or not it occurred at a freeway ( freeway $_{i}$ ), in addition to random effects for individual $i\left(v_{i}\right)$, site $j\left(\omega_{j}\right)$ and night $k\left(\theta_{k}\right)$, "Eq. 2":

$$
\operatorname{logit}\left(d_{i, j, k}\right)=\operatorname{logit}\left(D_{\text {sex }_{i}, \text { freeway }}\right)+v_{i}+\omega_{j}+\theta_{k}
$$

where $d_{i, j, k}$ is the probability of recapture for individual $i$ at site $j$ on night $k$. The variable $D_{j, k}$ is the base probability of recapture for individuals of $\operatorname{sex} j$ at site type $k$.
Survival rate was assumed to be constant over time, so the probability of an individual surviving a period of $t$ days between two trapping nights was equal to $s^{t / 365}$, where $s$ is its annual probability of survival. Survival rates for each of the two time periods (August 2005 to December 2006 and January 2007 to February 2008) were scaled to an annual time frame. As well as being a product of squirrel glider capture histories during the second survival period, the second survival period took into account whether an animal was modeled as alive or dead at the end of the first time period based on the probability of recapture in the first time period and its sighting history (Table 1).

Models were analyzed in WinBUGS Version 2.10 (Spiegelhalter et al. 2005). For each squirrel glider, capture histories were used to estimate the probability of being alive on each day that trapping occurred in any of the seven sample populations. Vague priors were placed on all parameters except annual survival of individuals in control sites, in which case an informative prior based on allometric data (McCarthy et al. 2008) and a previous study of squirrel gliders (van der Ree 2000, 2002) were used.

\section{Informative priors}

Two sources of prior information were used for survival rates of male and female squirrel gliders in control populations. Bayesian informative priors for male and female survival rates were developed using an allometric regression of survival rates on body mass for mammals (McCarthy et al. 2008) and a data set from a previous mark-recapture study of squirrel gliders (van der Ree 2000, 2002). These informative priors were used in the model described above, with the data collected in 2005-2008 forming the "data" component of this model.

\section{Allometric regression}

Body mass was used to predict annual survival of adult male and adult female squirrel gliders based on an allometric model and a worldwide data set of survival rates in mammals (McCarthy et al. 2008). Random effects were included for taxonomic order, species, study, and particular case within studies (for example, within one study, separate estimates for different years). Estimates of the mean body mass of male $(0.258 \mathrm{~kg})$ and female $(0.235 \mathrm{~kg})$ adult squirrel gliders in southeast Australia were obtained from van der Ree (2000). The estimated mean 
survival rate of adult squirrel gliders and the 95\% credible interval (in square brackets) was 0.55 [0.11, $0.87]$ for females and 0.56 [0.12, 0.87] for males. These values were obtained from 100,000 iterations after a burn-in of 200,000 iterations. A Bayesian credible interval expresses the region that contains the true value of the parameter with a defined probability (in this case, a 95\% probability that this interval contains the value of the parameter). This contrasts with a frequentist confidence interval, which says if the data were collected and an interval constructed in this way an infinite number of times, a particular percentage of the confidence intervals would contain the true mean (McCarthy 2007). Credible intervals and confidence intervals are often estimated in similar contexts but convey different information (McCarthy 2007).

\section{7-1998 mark-recapture data}

A mark-recapture study of squirrel gliders was conducted between November 1997 and June 1998 (van der Ree 2000, 2002) in strips of roadside woodland located approximately $2 \mathrm{~km}$ east and 2 $\mathrm{km}$ southeast of $\mathrm{C} 4$ and $\mathrm{C} 3$, respectively (Fig. 1). Trapping methods were similar to those used in this study (see van der Ree 2000, 2002 for more details). A capture history based on captures of 59 male and 81 female adult squirrel gliders was used in creating the informative prior. The capture history covered eight sampling sessions, with each session ranging between 10 and 17 nights. For each individual, captures within a sampling session were pooled so that an animal was considered captured in a particular sampling session if it was captured at least once. This was based on the assumption that no emigration or mortality would occur within each sampling session.

A modified version of a mark-recapture model developed by McCarthy and Masters (2005) was used to estimate the annual survival rate of adult squirrel gliders at all sites types. Data for male and female squirrel gliders were analyzed separately with this model, providing estimates for each. Additions to the model used by McCarthy and Masters (2005) were a function to scale the survival probability to an annual time frame, and random effects for recapture rates among sampling sessions and recapture rates among individual squirrel gliders. This meant that within the model, recapture rates could vary across time and among squirrel gliders, respectively.
To combine the two sources of prior information, posterior probability distributions obtained from the allometric regression were used as informative priors for the 1997-1998 mark-recapture model. The posterior distribution for this survival rate formed the informative prior of the 1997-1998 mark-recapture model. When using the allometric regression as informative priors for the 1997-1998 mark-recapture model, the mean survival rate had a posterior distribution with a mean and $95 \%$ credible interval of $0.73[0.54,0.88]$ for male squirrel gliders, and 0.66 [0.49, 0.83] for female squirrel gliders. Estimates were based on 100,000 iterations, after discarding a burn-in of 200,000 iterations. These estimates formed the informative prior distributions for survival rates in control populations for the 2005-2008 mark recapture model. The priors were modeled with beta distributions to constrain the values to the interval $[0,1]$.

\section{RESULTS}

\section{Trapping results}

A total of 184 squirrel gliders were captured at the seven sites between August 2005 and February 2008. Between August 2005 and mid-December 2006, 148 adult squirrel gliders ( 83 females and 65 males) were trapped at least once. Of these, 57 were captured within the control populations (34 females and 23 males), and 91 were captured within the freeway populations (49 females and 42 males). From January to mid-February 2008, 62 adult squirrel gliders were trapped ( 34 females and 28 males): 36 in the control populations (21 females and 15 males) and 26 in the freeway populations (13 of each sex). Of the 62 animals captured in 2008, 36 were new animals and the remainder were recaptures. During the three years of trapping, we did not detect animals moving among sites.

\section{5-2008 mark-recapture model}

The capture histories from the trapping of squirrel gliders from August 2005 to February 2008 formed the data component of the 2005-2008 markrecapture model. Within this model, two different priors were used for the parameters of survival rates of adult male and female squirrel gliders. The first were vague (uniform) distributions. The second were informative beta distributions based on 
estimates from the 1997-1998 mark-recapture model and a model describing the allometric relationship between body mass and survival rates developed by McCarthy et al. (2008).

\section{Probability of recapture in freeway populations}

The probability of recapture per night in freeway populations was measured separately for male and female squirrel gliders but with no fixed effect for the survival period (instead, there was a random effect for trapping "days"). Recapture rates were similar for male and female gliders. For male squirrel gliders, the mean and $95 \%$ credible intervals for the recapture rate were $0.20[0.10,0.37]$ with a vague prior for survival rates, and $0.19[0.10,0.36]$ with an informative prior for survival rates. For females, the recapture rate was 0.20 [0.11, 0.37] with a vague prior for survival rates, and $0.20[0.11$, 0.36 ] with an informative prior for survival rates (Table 2). The standard deviation of the three random effects for recapture rates indicates the variation in recapture rates among trap nights, sites, and individuals. With an informative prior for survival rates, the standard deviation with $95 \%$ credible intervals for these random effects was 0.38 $[0.11,0.65]$ for trap nights, $0.53[0.11,1.37]$ for sites, and $0.53[0.27,0.80]$ for individuals.

\section{Apparent annual survival rate}

Survival rate was estimated separately for each sex and survival period. These four parameters were estimated with and without informative priors. While the point estimates for the mean of the survival rate appeared higher in the first survival period, the $95 \%$ credible intervals overlapped between both survival periods and both sexes with and without an informative prior (Figs. 2 and 3, Table 2). As well as demonstrating similarity in estimates between the first and second survival periods, these estimates suggest that annual survival rates were consistently lower in freeway populations compared with control populations across the two survival periods, and that survival rates were lower in freeway populations for both males and females.

In the above estimates, greater precision was obtained when informative priors were placed on survival rates in control populations than when all parameters had a vague prior, with one exception: annual survival rates of males in freeway populations during the second survival period had a slightly lower precision when informative priors were used. The difference in precision between models with vague versus informative priors was greater for estimates of annual survival rates in control populations than estimates for freeway populations. In all cases, the difference in precision between estimates with and without informative priors was small (Table 2, Figs. 2 and 3).

\section{Relative apparent survival rate}

The survival rate of both male and female squirrel gliders in freeway populations was approximately one-third of that in control populations. An approximate ratio of one-third was evident with vague priors $($ mean $=0.40[0.25,0.61])$ and with informative priors $($ mean $=0.37[0.24,0.53])($ Fig. 4 , Table 2). The precision of estimates is represented by the size of their credible interval, where a comparatively smaller credible interval indicates greater precision. Including informative priors only slightly improved the precision of the estimate for the relative survival rate of squirrel gliders.

\section{DISCUSSION}

\section{Reduced apparent annual survival rate}

This study indicates that between August 2005 and February 2008, the apparent annual survival rate of squirrel gliders in populations near the Hume Freeway was one-third of the rate in populations located at least $5 \mathrm{~km}$ away (control populations). In control populations, squirrel gliders were exposed to a much lower traffic volume, and habitat was intersected by a road of much smaller width than the Hume Freeway. The rate of true survival and site fidelity, and therefore the rate of mortality and emigration, respectively, were not individually estimated in this study, so the low apparent annual survival rate in freeway populations may be due to an increased rate of mortality in freeway populations, higher rates of emigration from freeway populations, or a combination of both.

There is a large amount of evidence that roads, and more specifically vehicles, are a mortality risk for many species of wildlife (e.g., Groot Bruinderink and Hazebroek 1996, Lodé 2000, Clevenger et al. 2003, Ramp et al. 2005, Lovari et al. 2007). The 
Table 2. Parameter estimates from the 2005-2008 mark-recapture model using data from squirrel glider (Petaurus norfolcensis) populations in southeast Australia. For each parameter, two values are provided: the first was estimated with vague priors; the one underneath was estimated with informative priors for annual survival rates in control populations.

\begin{tabular}{|c|c|c|c|c|c|}
\hline Parameter & Sex & $\begin{array}{c}\text { Survival } \\
\text { period }\end{array}$ & Mean & S.D. & $\begin{array}{c}95 \% \text { credible } \\
\text { interval }\end{array}$ \\
\hline \multicolumn{6}{|c|}{ Relative apparent survival rate } \\
\hline & Combined & Combined & $\begin{array}{l}0.40 \\
0.37\end{array}$ & $\begin{array}{l}0.09 \\
0.07\end{array}$ & $\begin{array}{l}{[0.25,0.61]} \\
{[0.24,0.53]}\end{array}$ \\
\hline \multicolumn{6}{|c|}{ Apparent annual survival rate in control populations } \\
\hline & Male & First & $\begin{array}{l}0.78 \\
0.73\end{array}$ & $\begin{array}{l}0.15 \\
0.08\end{array}$ & $\begin{array}{l}{[0.45,0.99]} \\
{[0.57,0.87]}\end{array}$ \\
\hline & Female & First & $\begin{array}{l}0.67 \\
0.66\end{array}$ & $\begin{array}{l}0.14 \\
0.07\end{array}$ & $\begin{array}{l}{[0.40,0.92]} \\
{[0.52,0.79]}\end{array}$ \\
\hline & Male & Second & $\begin{array}{l}0.38 \\
0.60\end{array}$ & $\begin{array}{l}0.09 \\
0.08\end{array}$ & $\begin{array}{l}{[0.22,0.57]} \\
{[0.44,0.74]}\end{array}$ \\
\hline & Female & Second & $\begin{array}{l}0.52 \\
0.62\end{array}$ & $\begin{array}{l}0.09 \\
0.07\end{array}$ & $\begin{array}{l}{[0.35,0.69]} \\
{[0.48,0.75]}\end{array}$ \\
\hline \multicolumn{6}{|c|}{ Apparent annual survival rate in freeway populations } \\
\hline & Male & First & $\begin{array}{l}0.31 \\
0.27\end{array}$ & $\begin{array}{l}0.07 \\
0.06\end{array}$ & $\begin{array}{l}{[0.18,0.46]} \\
{[0.17,0.40]}\end{array}$ \\
\hline & Female & First & $\begin{array}{l}0.26 \\
0.25\end{array}$ & $\begin{array}{l}0.07 \\
0.05\end{array}$ & $\begin{array}{l}{[0.15,0.40]} \\
{[0.15,0.36]}\end{array}$ \\
\hline & Male & Second & $\begin{array}{l}0.15 \\
0.22\end{array}$ & $\begin{array}{l}0.05 \\
0.05\end{array}$ & $\begin{array}{l}{[0.08,0.26]} \\
{[0.14,0.33]}\end{array}$ \\
\hline & Female & Second & $\begin{array}{l}0.20 \\
0.23\end{array}$ & $\begin{array}{l}0.05 \\
0.05\end{array}$ & $\begin{array}{l}{[0.12,0.32]} \\
{[0.14,0.33]}\end{array}$ \\
\hline \multicolumn{6}{|c|}{ Probability of recapture in freeway populations } \\
\hline & Male & Combined & $\begin{array}{l}0.20 \\
0.19\end{array}$ & $\begin{array}{l}0.07 \\
0.06\end{array}$ & $\begin{array}{l}{[0.10,0.37]} \\
{[0.10,0.36]}\end{array}$ \\
\hline & Female & Combined & $\begin{array}{l}0.20 \\
0.20\end{array}$ & $\begin{array}{l}0.07 \\
0.06\end{array}$ & $\begin{array}{l}{[0.11,0.37]} \\
{[0.11,0.36]}\end{array}$ \\
\hline
\end{tabular}


Fig. 2. Apparent annual survival rate of male squirrel gliders (Petaurus norfolcensis) in control and freeway populations. Open circles are mean estimates with vague priors; shaded circles are estimates with informative priors. Bars are $95 \%$ credible intervals. Survival period refers to either of two time intervals over which apparent survival rates were estimated. The first survival period includes trap sessions between August 2005 and December 2006; the second includes sessions between January 2007 and February 2008.

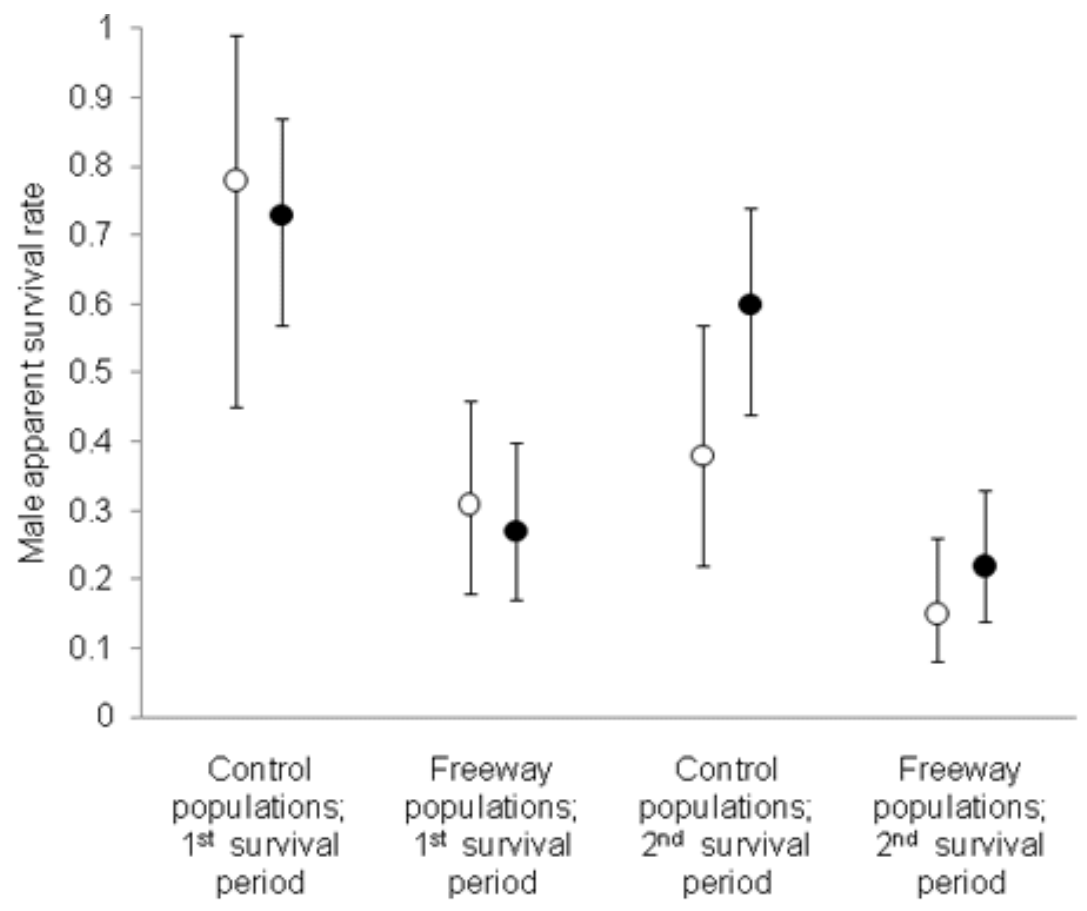

research linking road effects with consequences at the population level has identified a reduction in demographic rates (Foppen and Reijnen 1994, Mumme et al. 2000, Row et al. 2007), an increased risk of extinction (Gibbs and Shriver 2005), and a reduction in population densities or abundance (Fahrig et al. 1995, Marsh and Beckman 2004, Fahrig and Rytwinski 2009). A recent review of road effects on animal abundance showed considerable variation in the size and direction of road effects on animal abundance (Fahrig and Rytwinski 2009). Amphibians, reptiles, and large mammals were mostly negatively affected, while birds and medium-sized mammals were predominantly negatively affected or not affected. In contrast, for small mammals (the size category in which squirrel gliders fit), there was a pattern of positive or no effects on abundance associated with roads (Fahrig and Rytwinski 2009). Because we did not calculate abundance, we do not know whether the populations we sampled would have shown a similar pattern as those in Fahrig and Rytwinski's (2009) review. Differences between freeway and control sites in glider density or age structure may cause differences in survival, although we do not anticipate that this is the case.

Squirrel gliders do attempt to cross roads, and higher rates of crossing have been reported at locations where there were tall trees in the center median (Cesarini et al. 2010). Tall trees were present at one of the three freeway sites surveyed in this study, and in many other sections along this road. Depending on the height of and distance between launching and 
Fig. 3. Apparent annual survival rate of female squirrel gliders (Petaurus norfolcensis) in control and freeway populations. Open circles are mean estimates with vague priors; shaded circles are estimates with informative priors. Bars are $95 \%$ credible intervals. Survival period refers to either of two time intervals over which apparent survival rates were estimated. The first survival period includes trap sessions between August 2005 and December 2006; the second includes sessions between January 2007 and February 2008.

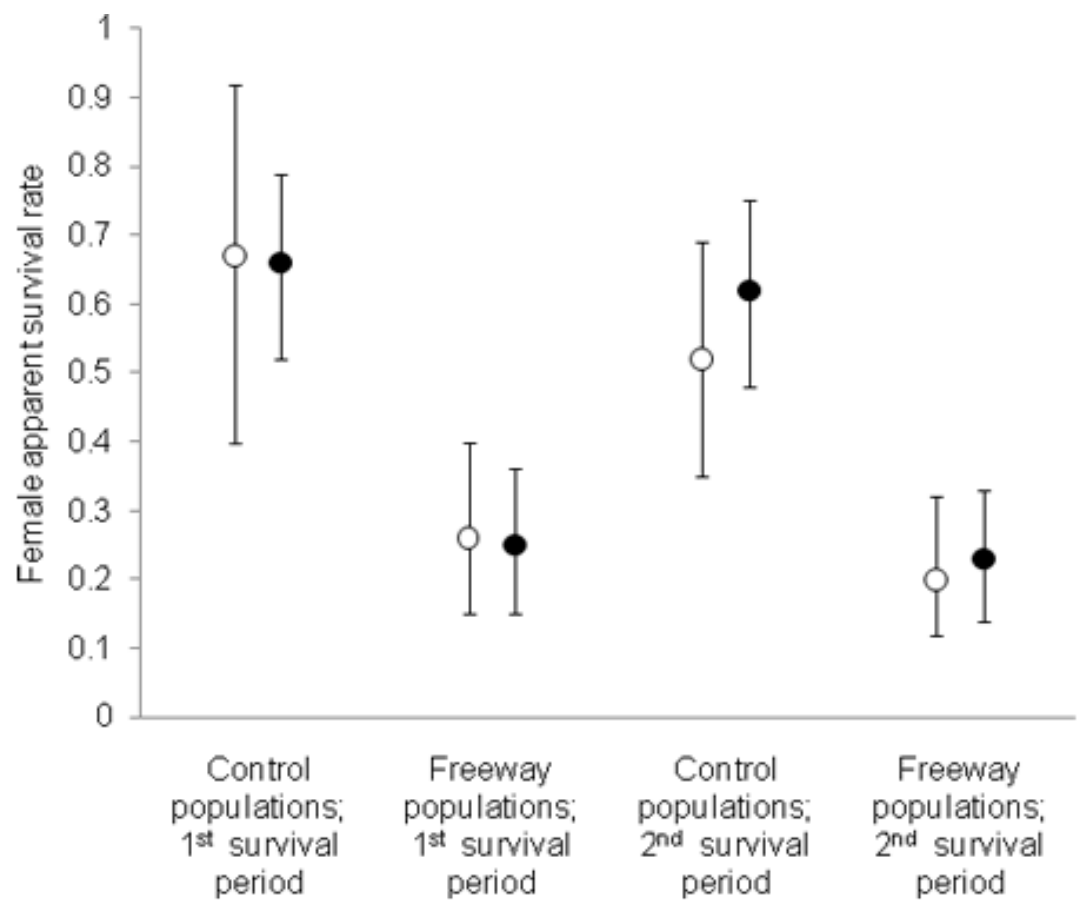

landing trees, and the angle that an animal takes in its glide, the glide profile may place an animal within the path of vehicles. Dead squirrel gliders have been found along the Hume Freeway, presumably dying after colliding with a vehicle. Higher predation rates along the freeway due, for example, to reduced concealment from potential predators and higher predator densities may also contribute to higher mortality rates along the freeway. Studies of predator densities along large roads have found inconsistent responses among species, with examples of positive, negative, and neutral population responses all seemingly evident (Meunier et al. 2000, Bautista et al. 2004, Fahrig and Rytwinski 2009). Whether predator populations are at higher densities along the Hume Freeway than populations at control sites is yet to be determined, as is qualification of whether this translates into higher predation rates of squirrel gliders along the freeway.

The presence of squirrel gliders at more than 30 sites along the Hume Freeway in southeast Australia indicates that the species is tolerant of roads with high traffic volume (van der Ree, unpublished data). However, an additional explanation for reduced apparent survival is that the road and traffic may alter emigration rates. Aspects of the roadside vegetation, the road itself, and disturbance by vehicles may attract or repel animals. Further study of the behavior of individuals is required to elucidate the importance of movement rates among populations along major roads. 
Fig. 4. Relative apparent survival rate (ratio of apparent annual survival in freeway populations to apparent annual survival in control populations) of male and female squirrel gliders (Petaurus norfolcensis) in southeast Australia, 2005-2008. The open circle is the mean estimate with vague priors; the shaded circle is the mean estimate with informative priors for apparent survival in control populations. Bars are $95 \%$ credible intervals.

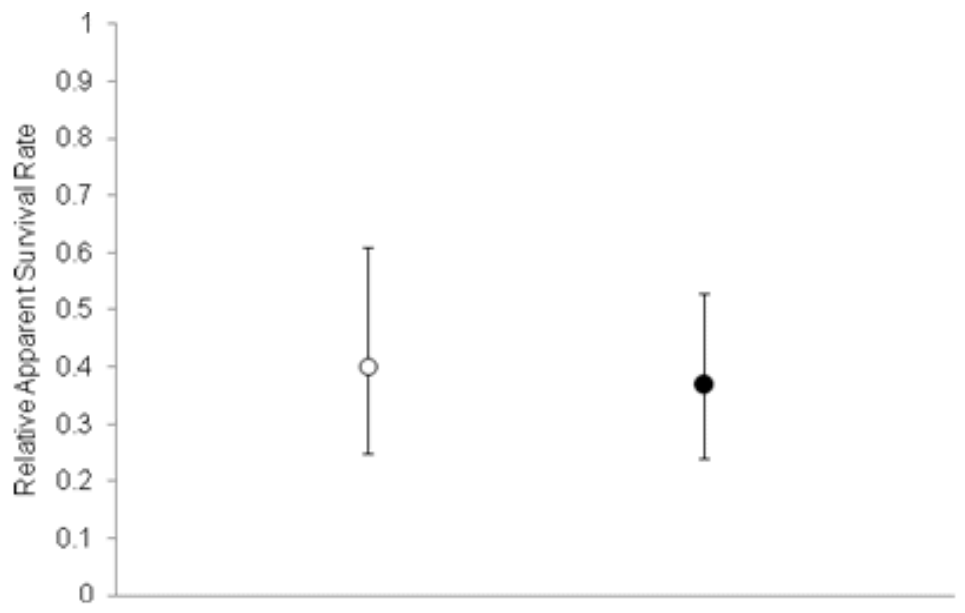

\section{Potential effects on the wider population}

It was estimated that approximately three-quarters of both male and female adult squirrel gliders are lost from freeway populations on an annual basis via mortality and/or emigration (Figs. 2 and 3, Table 2). Based on this estimate, a recruitment rate of three animals per remaining individual is required to maintain a stable population size. Without immigration, the annual natality rate (the number of offspring born per adult female) would need to be a minimum of six offspring (assuming an equal sex ratio), with the assumption that all reach the adult stage. However, this rate is considerably higher than the more likely annual natality rate of 1.7-2.4 found across a number of studies in eastern Australia (van der Ree 2000). Therefore, immigration appears to be critical for maintaining populations close to the Hume Freeway, which is consistent, although not definitively, with a proposal that these populations are sinks (i.e., natality is not high enough to compensate for mortality [Pulliam 1988]). This could reduce abundance of the wider population if an increased risk of mortality is associated with the freeway (see, for example, the discussion on ecological traps in Schlaepfer et al. 2002). The Eucalyptus woodland across the study area has been cleared considerably, and most woodland vegetation occurs as a network of linear strips. Continued immigration requires source populations as well as movement corridors, and in the study area, the network of linear strips provides habitat and connectivity (van der Ree 2002, van der Ree and Bennett 2003). The isolated single trees and small patches of trees in cleared farmland are also important components of habitat and connectivity (van der Ree et al. 2003).

In contrast, approximately one-third of squirrel gliders were lost annually from control populations as a consequence of mortality or emigration. This would require a recruitment rate of approximately one animal for every two remaining individuals to maintain a stable population size. This requires an average annual natality rate of two offspring per adult female, contingent on there being no immigration, on all offspring reaching the adult stage, and on an equal sex ratio. Assuming that neither control nor freeway populations are steadily increasing or decreasing in size, it seems probable that a greater proportion of each freeway population was derived from immigrated individuals than was the proportion of control populations. 


\section{Informative priors}

Ecologists have used Bayesian priors and metaanalyses to combine information from different sources (Downing et al. 1999, Hedges et al. 1999, Ellison 2004, McCarthy 2007). Some examples of information sources that have been used for Bayesian informative priors in ecological research are collateral studies (e.g., McCarthy and Masters 2005, Mackey et al. 2008), predictions based on patterns in life history (e.g., McCarthy and Masters 2005, McCarthy et al. 2008), and expert opinion (e. g., Martin et al. 2005). In this study, informative priors provided support for our estimates through similarities between estimates of relative survival with and without the use of prior information, and similarities between the prior information and estimates of apparent annual survival.

A number of ecological studies have improved the precision of model estimates by including Bayesian informative priors (e.g., Martin et al. 2005, McCarthy and Masters 2005, McCarthy et al. 2008). In our study, there was a small but noticeable improvement in precision for estimates of apparent annual survival rates when some prior information was included compared with using vague priors, but there was little or no improvement in the precision of the relative apparent survival rate when informative priors were used. This could be because models included only informative priors for apparent survival rates in control populations. Because the relative survival rate is also influenced by the apparent annual survival rate in freeway populations and the probability of recapture, prior information for these parameters could potentially improve the precision of the relative survival rate. Likewise, estimates of apparent annual survival in control and freeway populations could potentially be improved with the same information.

\section{Management of populations near roads}

The approach taken to manage squirrel glider populations near large roads may vary depending on the importance of maintaining connectivity among populations or reducing mortality rates (van der Ree 2006). A mitigation measure that improves one of these factors could potentially be detrimental to the other, and this will have implications for persistence of the wider population. As mentioned, squirrel gliders will glide across the road, with crossing rates highest when tall trees are present in the center median (Cesarini et al. 2010).
A recent trend to install glider poles (tall timber poles with a horizontal crossarm (van der Ree 2006, Ball and Goldingay 2008) may facilitate squirrel glider movement across the freeway. While glider poles and tall trees in the median may improve connectivity across the road, they may have negative consequences for populations if they increase mortality rates by placing gliding individuals in the path of oncoming vehicles. This may occur if poles are not of adequate height for animals to remain above vehicles given the distance to a second pole or tree. Alternatively, poles may be of adequate height to allow this; however, there is no guarantee that an animal will not glide at an angle that brings it to the level of vehicles.

An important next step in designing and evaluating mitigation options for gliders involves a comparison of crossing rates, apparent survival rates, and population density among the different treatment options and their effectiveness at increasing population viability (van der Ree et al. 2009). Information on fecundity and behavioral changes along roadsides before and after the implementation of mitigation measures will also inform analyses of population viability, and could contribute to management choices. Separation of apparent survival rates into true survival rates and site fidelity rates could also play a useful role in predicting the effect of mitigation measures on the wider population. For example, if apparent survival rates were to decrease with the implementation of mitigation, the assessment of the effectiveness of the technique could be very different depending on whether both or only one of mortality and emigration rates have increased. A range of techniques are available, including radio-telemetry, a more extensive mark-recapture framework, or a combination of mark-recapture methods with data on the recovery of dead animals. An overview of these techniques can be found in Sandercock (2003), and a more extensive description of some methods is provided in Hestbeck et al. 1991, Schwartz et al. 1993, and Joe and Pollock 2002.

There are increasing attempts across Europe, North America, and Australia to mitigate the barrier and mortality effects of roads and traffic on wildlife. Our study has shown that evaluating these mitigation approaches will be more informative if changes to population rates as well as behavioral responses are considered. For example, confirming that squirrel gliders will use a glider pole to traverse a road without documenting rates of mortality will only provide a partial story of success. A recent review 
of literature on the use and effectiveness of wildlife crossing structures indicated that most studies reported only use, and very few measured effectiveness (van der Ree et al. 2007). A thorough investigation of survival rates and the relative contribution of mortality and emigration are required to identify the nature and extent of the road problem and the appropriate form of mitigation required. Similarly, the effectiveness of mitigation efforts should evaluate the specific issue that is contributing most to reduced levels of population viability.

Responses to this article can be read online at: http://www.ecologyandsociety.org/voll5/iss3/art27/ responses/

\section{Acknowledgments:}

This research was supported by The Baker Foundation, the Australian Research Centre for Urban Ecology, Australian Research Council grants (LP0560443 and DP0985600), the Applied Environmental Decision Analysis hub of the Commonwealth Environment Research Facility, VicRoads, and the New South Wales Roads and Traffic Authority. We thank J. Carey, P. Vesk, A. Taylor, P. Sunnucks, and M. Burgman for comments on various aspects of this research. In addition, we appreciate the comments provided by three anonymous reviewers. Fieldwork was approved by University of Melbourne Animal Ethics Committee: 05141 and 0810924, and the Department of Sustainability and Environment issued trapping permits: 10003061 and 10004763.

\section{LITERATURE CITED}

Akçakaya, R. H., and P. Sjögren-Gulve. 2000. Population viability analysis in conservation planning: an overview. Ecological Bulletins 48:921.

Ball T., and R. Goldingay. 2008. Can wooden poles be used to reconnect habitat for a gliding mammal? Landscape and Urban Planning 87:140-146.

Bautista, L. M., J. T. García, R. G. Calmestra, C. Palacín, C. A. Martín, M. B. Morales, R. Bonal, and J. Viñuela. 2004. Effect of weekend traffic on the use of space by raptors. Conservation Biology 18:726-732.

Bernhardt-Römermann, M., M. Kirchner, T. Kudernatsch, G. Jakobi, and A. Fischer. 2006. Changed vegetation composition in coniferous forests near to motorways in Southern Germany: the effects of traffic-born pollution. Environmental Pollution 143:572-581.

Bignal, K. L., M. R. Ashmore, A. D. Headley, K. Stewart, and K. Weigert. 2007. Ecological impacts of air pollution from road transport on local vegetation. Applied Geochemistry 22:1265-1271.

Brown, G. P., B. L. Phillips, J. K. Webb, and R. Shine. 2006. Toad on the road: Use of roads as dispersal corridors by cane toads (Bufo marinus) at an invasion front in tropical Australia. Biological Conservation 133:88-94.

Cesarini, S., R. van der Ree, P. Sunnucks, J. Moore, and A. Taylor. 2010. Large gaps in canopy reduce road crossing by a gliding mammal. Ecology and Society in press.

Claridge, A. W., and R. van der Ree. 2004. Recovering endangered populations in fragmented landscapes: the squirrel glider Petaurus norfolcensis on the south-west slopes of New South Wales. Pages 678-687 in D. Lunney, editor. Conservation of Australia's forest fauna. Second edition. Royal Zoological Society of New South Wales, Mosman, Australia.

Clevenger, A. P., B. Chruszez, and K. E. Gunson. 2003. Spatial patterns and factors influencing small vertebrate fauna road-kill aggregations. Biological Conservation 109:15-26.

Converse, S. J., J. B. Iverson, and J. A. Savidge. 2005. Demographics of an ornate box turtle population experiencing minimal human-induced disturbances. Ecological Applications 15:21712179.

Downing, J. A., C. W. Osenberg, and O. Sarnelle. 1999. Meta-analysis of marine nutrient-enrichment experiments: variation in the magnitude of nutrient limitation. Ecology 80:1157-1167.

Drechsler, M., and M. A. Burgman. 2004. Combining population viability analysis with decision analysis. Biodiversity and Conservation 13:115139. 
Ellison, A. M. 2004. Bayesian inference in ecology. Ecological Letters 7:509-520.

Fahrig, L., J. H. Pedlar, S. E. Pope, P. D. Phillip, and J. F. Wegner. 1995. Effects of road traffic on amphibian density. Biological Conservation 73:177-182.

Fahrig, L., and T. Rytwinski. 2009. Effects of roads on animal abundance: an empirical review and synthesis. Ecology and Society 14(1):21. [online]. URL: http://www.ecologyandsociety.org/vol14/iss1/ art21\%.

Foppen, R., and R. Reijnen. 1994. The effects of car traffic on breeding bird populations in woodland. II. Breeding dispersal of male willow warblers (Phylloscopus trochilus) in relation to the proximity of a highway. Journal of Applied Ecology 31:95-101.

Forman, R. T. T., and R. D. Deblinger. 2000. The ecological road-effect zone of a Massachusetts (USA) suburban highway. Conservation Biology 14:36-46.

Gibbs, J. P., and G. Shriver. 2005. Can road mortality limit populations of pool-breeding amphibians? Wetlands Ecology and Management 13:281-289.

Gill, J. A., K. Norris, and W. J. Sutherland. 2001. Why behavioral responses may not reflect the population consequences of human disturbance. Biological Conservation 97:265-268.

Groot Bruinderink, G. W. T. A., and E. Hazebroek. 1996. Ungulate traffic collisions in Europe. Conservation Biology 10:1059-1067.

Hedges, L. V., J. Gurevitch, and P. S. Curtis. 1999. The meta-analysis of response ratios in experimental ecology. Ecology 80:1150-1156.

Hestbeck, J. B., J. D. Nichols, and R. A. Malecki. 1991. Estimates of movement and site fidelity using mark-resight data of wintering Canada geese. Ecology 72:523-533.

Huijser, M. P., J. W. Duffield, A. P. Clevenger, R. J. Ament, and P. T. McGowen. 2009. Cost-benefit analyses of mitigation measures aimed at reducing collisions with large ungulates in the United States and Canada: a decision support tool. Ecology and
Society 14(2):2. [online] URL: http://www.ecology andsociety.org/vol14/iss2/art15/.

Joe, M., and K. H. Pollock. 2002. Separation of survival and movement rates in multi-state tagreturn and capture-recapture models. Journal of Applied Statistics 29:373-384.

Kerr, J. T., and D. T. Currie. 1995. Effects of human activity on global extinction risk. Conservation Biology 9:1528-1538.

Kerth, G., and M. Melber. 2009. Species-specific barrier effects of a motorway on the habitat use of two threatened forest-living bat species. Biological Conservation 142:270-279.

Lande, R. 1998. Anthropogenic, ecological and genetic factors in extinction and conservation. Researches on Population Ecology 40:259-269.

Lodé, T. 2000. Effect of a motorway on mortality and isolation of wildlife populations. Ambio 29:163166.

Lovari, S., A. Sforzi, C. Scala, and R. Fico. 2007. Mortality parameters of the wolf in Italy: Does the wolf keep himself from the door? Journal of Zoology 272:117-124.

Mackey, B. L., J. W. Durban, S. J. Middlemas, and P. M. Thompson. 2008. A Bayesian estimate of harbour seal survival using sparse photoidentification data. Journal of Zoology 274:18-27.

Marschall, E. A., and L. B. Crowder. 1996. Assessing population responses to multiple anthropogenic effects: a case study with brook trout. Ecological Applications 6:152-167.

Marsh, D. M., and N. G. Beckman. 2004. Effects of forest roads on the abundance and activity of terrestrial salamanders. Ecological Applications 14:1882-1891.

Martin, T. G., P. M. Kuhnert, K. Mengersen, and H. P. Possingham. 2005. The power of expert opinion in ecological models using Bayesian methods: impact of grazing on birds. Ecological Applications 15:266-280.

McCallum, H. 2000. Population parameters: estimation for ecological models. Blackwell Science, Oxford, UK. 
McCarthy, M. A. 2007. Bayesian methods for ecology. Cambridge University Press, Cambridge, UK.

McCarthy, M. A., R. Citroen, and S. C. McCall. 2008. Allometric scaling and Bayesian priors for annual survival of birds and mammals. The American Naturalist 172:216-222.

McCarthy, M.A., and P. Masters. 2005. Profiting from prior information in Bayesian analyses of ecological data. Journal of Applied Ecology 42:1012-1019.

Merriam, G., M. Kozakiewicz, E. Tsuchiya, and K. Hawley. 1989. Barriers as boundaries for metapopulations and demes of Peromyscus leucopus in farm landscapes. Landscape Ecology 2:227-235.

Meunier, F. D., C. Verheyden, and P. Jouventin. 2000. Use of roadsides by diurnal raptors in agricultural landscapes. Biological Conservation 92:291-298.

Mumme, R. L., S. J. Schoech, and G. E. Woolfenden. 2000. Life and death in the fast land: demographic consequences of road mortality in the Florida scrub-jay. Conservation Biology 14:501512.

Parendes, L. A., and J. A. Jones. 2000. Role of light availability and dispersal in exotic plant invasions along roads and streams in the $\mathrm{H}$. J. Andrews Experimental Forest, Oregon. Conservation Biology 14:64-75.

Parris, K. M., and A. Schneider. 2009. Impacts of traffic noise and traffic volume on birds of roadside habitats. Ecology and Society 14(1):29. [online] URL: http://www.ecologyandsociety.org/vol14/iss1/ $\underline{\operatorname{art29}}$.

Parris, K. M., M. Velik-Lord, and J. M. A. North. 2009. Frogs call at a higher pitch in traffic noise. Ecology and Society 14(1):25. [online] URL: http:/ /www.ecologyandsociety.org/vol14/iss 1/art25/.

Pulliam, H. R. 1988. Sources, sinks and population regulation. The American Naturalist 132:652-661.

Ramp, D., J. Caldwell, K. A. Edwards, D. Warton, and D. B. Croft. 2005. Modelling of wildlife fatality hotspots along the Snowy Mountain Highway in New South Wales, Australia. Biological Conservation 126:474-490.

Row, J. R., G. Blouin-Demers, and P. J. Weatherhead. 2007. Demographic effects of road mortality in black ratsnakes (Elaphe obsoleta). Biological Conservation 137:117-124.

Ruggiero, L. F., G. D. Hayward, and J. R. Squires. 1994. Viability analysis in biological evaluations: concepts of population viability analysis, biological population, and ecological scale. Conservation Biology 8:364-372.

Sandercock, B. K. 2003. Estimation of survival rates for wader populations: a review of markrecapture methods. Wader Study Group Bulletin 100:163174.

Schlaepfer, M. A., M. C. Runge, and P. W. Sherman. 2002. Ecological and evolutionary traps. Trends in Ecology and Evolution 17:474-480.

Schwarz, C. J., J. F. Schweigert, and A. N. Arnason. 1993. Estimating migration rates using tag recovery data. Biometrics. 49:177-193.

Spiegelhalter, D. J., J. A. Thomas, N. G. Best, and D. Lunn. 2005. WinBUGS user manual, version 2.10. MRC Biostatistics Unit, Cambridge, UK.

Turner II, B. L., W. C. Clark, R. W. Kates, J. F. Richards, J. T. Mathews, and W. B. Meyer, editors. 1990. The earth as transformed by human action: global and regional changes in the biosphere over the past 300 years. Cambridge University Press, Cambridge, UK.

van der Grift, E., and R. Pouwels. 2006. Restoring habitat connectivity across transport corridors: identifying high-priority locations for defragmentation with the use of an expert-based model. Pages 205231 in J. Davenport and J. L. Davenvport, editors. The ecology of transportation: managing mobility for the environment. Springer Dordrecht, The Netherlands.

van der Ree, R. 2000. Ecology of arboreal marsupials in a network of remnant linear habitats. Dissertation. Deakin University, Victoria, Australia.

van der Ree, R. 2002. The population ecology of the squirrel glider (Petaurus norfolcensis) within a 
network of remnant linear habitats. Wildlife Research 29:329-340.

van der Ree, R. 2006. Road upgrade in Victoria a filter to the movement of the endangered squirrel glider (Petaurus norfolcensis): results of a pilot study. Ecological Management and Restoration 7:226-228.

van der Ree, R., and A. F. Bennett. 2003. Home range of the squirrel glider (Petaurus norfolcensis) in a network of remnant linear habitats. Journal of Zoology 259:327-336.

van der Ree, R., A. F. Bennett, and D. C. Gilmore. 2003. Gap-crossing by gliding marsupials: thresholds for use of isolated woodland patches in an agricultural landscape. Biological Conservation 115:241-249.

van der Ree, R., D. Heinze, M. A. McCarthy, and I. Mansergh. 2009. Wildlife tunnel enhances population viability. Ecology and Society 14(2):7. [online] URL: http://www.ecologyandsociety.org/vol14/ iss $2 / \operatorname{art} 7 /$.

van der Ree, R., and G. C. Suckling. 2008. Squirrel glider. Pages 235-236 in S. Van Dyck and R. Strahan, editors. Mammals of Australia. Third edition. New Holland Publishers, Sydney, Australia.

van der Ree R., E. A. van der Grift, C. Mata, and F. Suarez. 2007. Overcoming the barrier effect of roads - how effective are mitigation strategies? An international review of the effectiveness of underpasses and overpasses designed to increase the permeability of roads for wildlife. Pages 423-431 in C. L. Irwin, D. Nelson and K. P. McDermott, editors. International Conference on Ecology and Transportation. Center for Transportation and The Environment, North Carolina State University, Raleigh, North Carolina, Little Rock, Arkansas, USA.

Yasué, M., and P. Dearden. 2006. The potential impact of tourism development on habitat availability and productivity of Malaysian plovers Charadrius peronii. Journal of Applied Ecology 43:978-989. 